
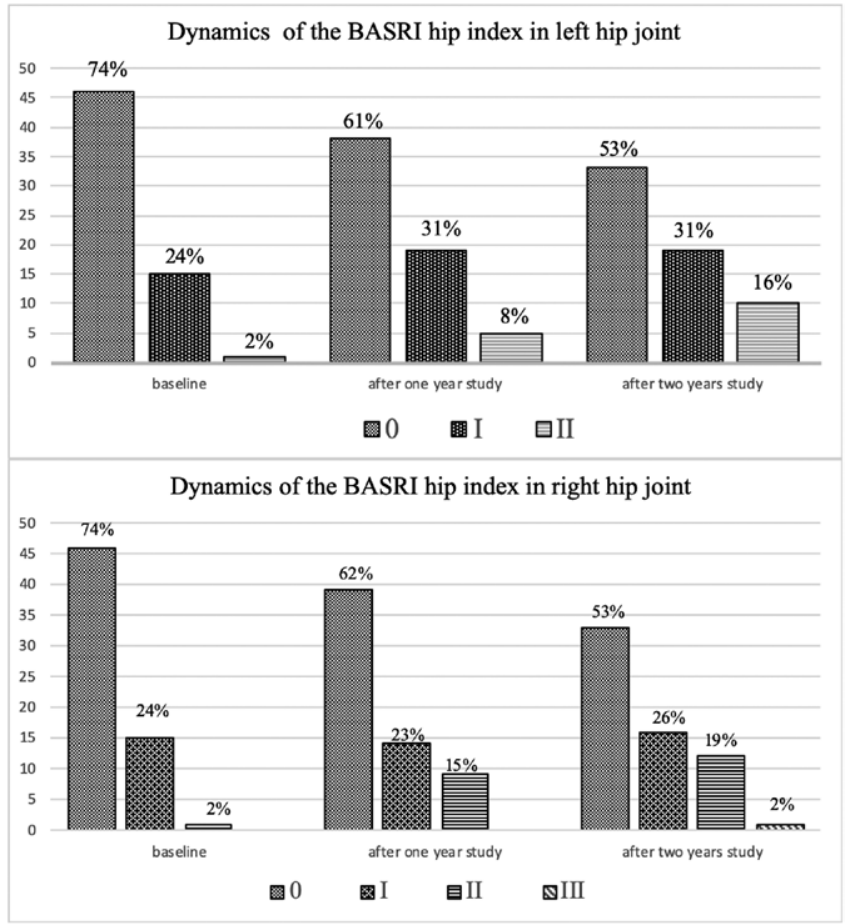

A comparative analysis of the groups revealed that progression is more common in men and in younger people $(p<0.05)$. In other parameters presented in Table 1, the groups did not differ from each other.

\begin{tabular}{|c|c|c|c|}
\hline Parameter & $\begin{array}{c}\Delta \text { BASRI hip }=0 \\
n=39\end{array}$ & $\begin{array}{c}\Delta \text { BASRI hip }>0 \\
n=23\end{array}$ & $\mathrm{p}$ \\
\hline $\operatorname{Sex}(m / w), n$ & $15 / 24$ & $17 / 6$ & $<0,05^{\star}$ \\
\hline $\begin{array}{l}\text { Duration of the disease months., } \\
\text { Me }[25 ; 75 \text { percentile }]\end{array}$ & $22[7 ; 36]$ & $24[18,8 ; 24,8]$ & $>0,05$ \\
\hline Age, years, Me $[25 ; 75$ percentile] & $29[25,5 ; 32,5]$ & $26,5[23,2 ; 28,7]$ & $<0,05^{\star}$ \\
\hline BASDAI, Me [25;75 percentile] & $3,6[2,1 ; 5,2]$ & $3,45[1,1 ; 5,2]$ & $>0,05$ \\
\hline BASFI, Me $[25 ; 75$ percentile] & $1,5[0,5 ; 2,8]$ & $0,7[0,3 ; 2,4]$ & $>0,05$ \\
\hline ASDAS (CRP), Me [25; 75 percentile] & $2,5[1,6 ; 3,35]$ & $2,4[1,25 ; 3,45]$ & $>0,05$ \\
\hline $\mathrm{ESR}, \mathrm{mm} / \mathrm{h}, \mathrm{Me}[25 ; 75$ percentile $]$ & $8[6 ; 22]$ & $10[5 ; 28,75]$ & $>0,05$ \\
\hline CRP, mg/L, Me [25; 75 percentile] & $5,3[1,3 ; 24,5]$ & $5,2[1,1 ; 23,4]$ & $>0,05$ \\
\hline Peripheral Arthritis, n\% & $12(32 \%)$ & $5(22 \%)$ & $>0,05$ \\
\hline
\end{tabular}

Conclusion: it has been shown that in some patients with axSpA already in the first years of the disease, radiological signs of $\mathrm{HJ}$ destruction are detected. The progression of coxitis was not dependent on the activity of the disease and was more often detected in men than in women.

Disclosure of Interests: Ekaterina Agafonova: None declared, Tatiana Dubinina Speakers bureau: Novartis, BIOCAD, MSD, Pfaizer, Abbvie, UCB, Shandor Erdes: None declared, Daria Rumiantceva: None declared DOI: 10.1136/annrheumdis-2020-eular.1110

\section{AB1074 FEATURES OF COMBINED USE OF BIOMARKERS AND VISUALIZATION METHODS FOR DIAGNOSIS OF HEART DAMAGE IN PATIENTS WITH RHEUMATOID ARTHRITIS}

N. Aleksandrova ${ }^{1}$, V. Aleksandrov ${ }^{1}$, L. Shilova ${ }^{2}$, A. Aleksandrov ${ }^{1,2}$ I. Zborovskaya ${ }^{1} .{ }^{1}$ Federal State Budgetary Institution «Research Institute of Clinical and Experimental Rheumatology named after A.B. Zborovsky", Volgograd, Russian Federation; ${ }^{2}$ Volgograd State Medical University, Department of Hospital Therapy, Volgograd, Russian Federation

Background: In rheumatoid arthritis (RA), the endocardium is involved in the inflammatory process, which is caused by immunopathogenetic mechanisms involving CD4 +, T-cells and proinflammatory macrophages. Minor changes in the cardiovascular system can be successfully detected by ultrasound in patients with RA.

Objectives: to improve the quality of non-invasive diagnostics of heart disease in patients with RA.

Methods: 57 patients with RA were under observation: 7 men and 50 women aged from 26 to 70 years; mean age $50.45 \pm 10.12$ years; activity (according to
DAS28) was low for $3.5 \%$, medium for $86 \%$, and high for $10.5 \%$. Immunological examination included determination of serum IgM-RF, CRP, antibodies to cyclic citrulline peptide (anti-CCP), antibodies to modified vimentin (anti-MCV), antibodies to antigen RA33, levels of angiopoietin-like proteins 3 (ANGPTL3) and 4 (ANGPTL4) types (classical ELISA test), as well as the detection of IgG antibodies to 5'-nucleotidase (5'-NT) and xanthine oxidase (XO) (modified ELISA test) Data from ultrasound, magnetic resonance (MRT) and computer (CT) tomography were used in assessing the state of the heart structures.

Results: The pathology of cardiovascular system was diagnosed in $28(49.1 \%)$ patients with RA. Signs of the heart damage were noted in $33.3 \%$ of cases (pericarditis and valvular heart disease were most often detected). In groups of patients with RA with elevated levels of antibodies to 5'-NT and XO (compared with RA patients with normal parameters), there was a significantly more frequent heart damage (for antibodies to $5^{\prime}-\mathrm{NT}: \mathrm{x}^{2}=3.8, \mathrm{p}=0.047$; for antibodies to $X O: x^{2}=3.92, p=0.041$ ). It was discovered that in all patients with an increased level of antibodies to XO, one of the lesions of the heart valvular apparatus of varying severity was noted. According to ultrasound data (usually confirmed by CT and / or MRT), signs of valvular dysfunction were found in 21 (36.8\%) patients with RA. The high frequency of mitral prolapse $(28.6 \%)$ may be associated with the presence of a chronic inflammatory process that is able to accelerate the development of atherosclerosis and heart disease in RA patients. A tendency to an increase in the prevalence of mitral prolapse in patients with a longer duration of the disease $(p=0.062)$ and with high levels of serum ANGPTL4 $(p=0.058)$ was found.

One of the main factors leading to the development of vascular pathology in RA is the accumulation of reactive oxygen intermediate. Antibodies to XO can affect the biochemical activity of the enzyme in the serum of patients with RA, stimulating the increased formation of $\mathrm{O}$-form $\mathrm{XO}$, which has a pronounced prooxidant effect (especially to lipids). ANGPTL4, acting as a potent inhibitor of endothelial lipoprotein lipase, can suppress the release of non-esterified fatty acids and their transfer to the heart muscle.

Conclusion: To identify subclinical signs of involvement of cardiovascular system in the pathological process in the early asymptomatic stages of RA, it is advisable to use imaging techniques in combination with immunological markers of heart damage, which can be especially useful for screening, diagnostic evaluation and determining cardiovascular risk.

Disclosure of Interests: None declared

DOI: 10.1136/annrheumdis-2020-eular.2588

\section{$\mathrm{AB} 1075$ \\ PRESENCE POWER DOPPLER ULTRASOUND AS A PREDICTOR OF RADIOGRAPHIC DAMAGE IN PATIENTS WITH RHEUMATOID ARTHRITIS}

O. Alekseeva ${ }^{1}$, A. Smirnov ${ }^{1}$, D. Kudinsky ${ }^{1}$, S. Glukhova ${ }^{1}$, A. Volkov ${ }^{1}$,

E. Nasonov'. 'V.A. Nasonova Research Institute of Rheumatology, Diagnostic department, Moscow, Russian Federation; ${ }^{2}$ V.A. Nasonova Research Institute of Rheumatology, Chief researcher, Moscow, Russian Federation

Background: Rheumatoid arthritis (RA) is a chronic inflammatory disease that leads to destructive changes and dysfunction of the joints. Ultrasound (US) is used in current practice as an early diagnostic method for detecting structural damage to articular surfaces. US changes in early RA are considered as one of the ways of predicting disease outcomes.

Objectives: to detect power doppler (PD) contribution in evaluation of radiographic RA progression in long term.

Methods: 85 RA pts, mean age $53,0[44,0 ; 61,0]$ yrs, mean disease duration 8 $[4 ; 24]$ months were treated by Treat-To-Target concept. After first year of therapy management was following real clinical practice rules until the termination of the study (4 years FUP). The wrist, MCP2 and MCP3, PIP2, PIP3, MTP2 and MTP5 joints of the clinically dominant side were examined by US (GS and PD). Clinical, laboratory parameters and US examination was performed at baseline, at Mo $3,6,9$ and 12 . The $X$-ray was conducted before treatment and in the end of the study. Structural damage progression was evaluated by change in the Sharp van der Heijde score $(\triangle \mathrm{SHS})$ between baseline and 4 year.

We categorized pts into 5 groups according to the occurrence of positive PD: 1) without PD throughout the observational period [the negative (N)], 2) positive PD limited to the period from the baseline to Mo 3 [the therapeutic response (R)], 3) positive PD limited to the period from the baseline to Mo 6-9 [the therapeutic late-response (LR)], 4) intermittent occurrence of $\mathrm{PD}$ in the observational period [the intermittently positive (IP)] and 5) with persistent positive PD throughout the observational period [the persistently positive (PP)]

Results: $80 \%$ of pts had PD synovitis at baseline. PD-synovitis dropped from $2[1,0 ; 6,0]$ to $0[0,0 ; 2,0]$ scores at Mo 12 . RA progression by 4 years FUP was identified in $13 \%$ of pts. The $\mathrm{X}$-ray erosion score at 4 years FUP in these groups - N, R, LR, IP and PP - were dependent by PD from baseline to Mo 12 (mean level $1[0 ; 2] ; 2[0 ; 4], 3[0 ; 5], 1[0 ; 2]$ and $4,5[1 ; 10]$ respectively), but statistically significant differences were found between $\mathrm{N}$ and $\mathrm{PP}$ groups. 